\title{
KAJIAN RETORIKA KIAS SINDIR DALAM BAHASA MELAYU BENGKULU
}

\author{
Vebbi Andra
}

\begin{abstract}
Abstrak:
The aim of this research is to study satire simile rhetoric in Bengkulunese Malay language, either in every sort or its pragmatic function. The use method was the descriptive method. The data colletion technique has been done with observation study and interview. Whereas the data analysis was based on the technique of transcribing, identifying, classifying, and concluding. The research object was satire simile rhetoric in Bengkulunese Malay language. The result of the research show, that the sort of satire simile rhetoric in Bengkulunese Malay language was divided into aphorism and parable. While the pragmatic function of satire simile rhetoric in Bengkulunese Malay language, based on its function could be classified into satire on deed (attitude) was done by a person or a group of persons and advice (teaching guidance) by meant a person or a group of persons could live well.
\end{abstract}

Key words: rhetoric, satire simile, Bengkulunese Malay language

\section{Pendahuluan}

Sejak zaman dahulu dalam pergaulan sehari-hari, masyarakat suku Melayu Bengkulu di dalam berbahasa sering menggunakan kias sindir. Penggunaan kias sindir oleh masyarakat suku Melayu Bengkulu merupakan bentuk dari retorika, yang memperlihatkan wujud kearifan lokal masyarakat suku Melayu Bengkulu dalam menyampaikan suatu maksud tertentu.

Retorika kias sindir dalam bahasa Melayu Bengkulu sebagai bagian dari budaya, tentu saja harus tetap dijaga dan dilestarikan. Melihat pentingnya peranan retorika kias sindir dalam bahasa Melayu Bengkulu sebagai inventaris dari budaya, maka retorika kias sindir dalam bahasa Melayu Bengkulu perlu mendapatkan perhatian dari berbagai pihak agar dapat dibina dan dikembangkan. Hal ini dilakukan sebagai upaya untuk mempertahankan retorika kias sindir dalam bahasa Melayu Bengkulu, dari pergeseran dan bahkan musnahnya kias sindir tersebut. Dengan pembinaan dan pengembangan terhadap retorika kias sindir dalam bahasa Melayu Bengkulu, diharapkan nantinya kias sindir tersebut dapat diwariskan ke generasi berikutnya.

Permasalahan dalam penelitian ini ialah menyangkut tentang apa sajakah jenis dan makna pragmatik dari retorika kias sindir dalam bahasa Melayu Bengkulu. Tujuan penelitian ini adalah diharapkan dapat memperoleh deskripsi tentang jenis dan makna pragmatik dari retorika kias sindir dalam bahasa Melayu Bengkulu. Sedangkan manfaat penelitian ini, yaitu berguna bagi pembelajaran bahasa, sastra Indonesia dan daerah, khususnya bagi sekolah-sekolah di Provinsi Bengkulu, dalam mempelajari dan memperkaya pemahaman siswa mengenai berbagai jenis dan makna pragmatik dari retorika kias sindir yang terdapat dalam bahasa Melayu Bengkulu.

\section{Metodologi Penelitian}

Metode yang digunakan dalam penelitian ini adalah metode deskriptif kualitatif, hal ini disebabkan peneliti menitikberatkan pada penggunaan 
instrumen orang sebagai alat pengumpulan datanya. Instrumen yang dimaksud dalam penelitian ini adalah peneliti nantinya berperan sebagai instrumen utama penelitian (human instrument) (Sugiyono, 2005:2). Lokasi penelitian dilakukan pada saat berlangsungnya peristiwa komunikasi (event of communication) di dalam masyarakat suku Melayu Bengkulu. Sedangkan sumber data adalah asal peneliti memperoleh data yang dimaksud dan yang diinginkan (Sudaryanto, 1990:33). Berdasarkan pandangan tersebut, maka sumber data dalam penelitian ini adalah interaksi bahasa yang terjadi antara penutur dan mitra tutur bahasa Melayu Bengkulu saat berlangsungnya peristiwa komunikasi (event of communication) di dalam masyarakat suku Melayu Bengkulu. Menurut Sudaryanto (1990:3) data adalah bahan penelitian. Berdasarkan pendapat tersebut maka data dalam penelitian ini ialah berupa penggunaan retorika kias sindir yang berbentuk pepatah dan perumpamaan oleh penutur bahasa Melayu Bengkulu.

Teknik pengumpulan data yang digunakan dalam penelitian ini adalah teknik observasi dan teknik wawancara. Menurut Margono (2005:158) observasi merupakan teknik pengamatan dan pencatatan secara sistematik terhadap gejala yang tampak pada objek penelitian. Sedangkan teknik wawancara, dapat dipahami sebagai proses tanyajawab dalam penelitian yang berlangsung secara lisan, dalam mana dua orang atau lebih bertatap muka mendengarkan secara langsung informasi-informasi atau keteranganketerangan (Narbuko dan Achmadi, 2005:83), dan teknik analisis data yang digunakan dalam penelitian ini adalah transkripsi, identifikasi, klasifikasi, dan kesimpulan. Sedangkan teknik pemeriksaan keabsahan data dapat dilihat melalui kredibilitas, transferabilitas,dependabilitas, dan konfirmabilitas.

\section{Temuan Penelitian dan Pembahasan}

a) Temuan penelitian

Penelitian ini dilakukan di Kelurahan Kebun Keling Kecamatan Teluk Segara Kota Bengkulu. Pemilihan lokasi tersebut dikarenakan wilayahnya merupakan perkampungan masyarakat suku Melayu Bengkulu yang diperkirakan sudah ada sejak tahun 1940-an. Kelurahan Kebun Keling sendiri baru dibentuk pada tahun 1982, setelah sebelumnya merupakan wilayah kedatukan dan kepemangkuan (Pemerintah Kota Bengkulu, 2010:1). Adapun temuan penelitian secara rinci, dapat dilihat melalui penjelasan berikut:

\section{(1) Pepatah}

Pepatah sebenarnya merupakan suatu kalimat kias yang berisi nasihat atau ajaran yang berasal dari orangorang yang memiliki pengetahuan mendalam tentang kehidupan. Adapun kias sindir yang berbentuk pepatah, berdasarkan makna pragmatik yang terkandung di dalamnya dapat dikelompokkan menjadi dua jenis yang berbeda, yaitu sindiran, dan nasihat.

\section{(a) Sindiran}

Sindiran adalah suatu acuan yang ingin mengatakan sesuatu dengan makna atau maksud berlebihan dari apa yang terkandung dalam rangkaian katakatanya (Keraf, 2000:143). Oleh karena itu, dapatlah dipahami bahwa sindiran merupakan suatu pernyataan yang digunakan untuk menyampaikan suatu 
maksud yang berupa ejekan. Adapun rincian Temuan penelitian mengenai makna pragmatik pepatah yang berupa sindiran, dapat dilihat pada tabel berikut ini:

Tabel 1: Klasifikasi Pepatah Berdasarkan Makna Pragmatik Berupa Sindiran

\begin{tabular}{|c|c|c|c|}
\hline No & Patos & Etos & Logos \\
\hline 1 & $\begin{array}{l}\text { Bujang baru } \\
\text { naik bekeris }\end{array}$ & $\begin{array}{lr}\text { Seseorang } & \text { yang } \\
\text { merasa hebat } \\
\text { karena baru } \\
\text { memiliki sesuatu }\end{array}$ & Sindiran \\
\hline 2 & $\begin{array}{l}\text { Bodoh idak } \\
\text { nurut pintar } \\
\text { idak mimpin }\end{array}$ & $\begin{array}{l}\text { Pemimpin yang } \\
\text { tidak tahu dan } \\
\text { bisa apa-apa } \\
\text { dalam berkerja. }\end{array}$ & Sindiran \\
\hline 3 & $\begin{array}{l}\text { Gerobak } \\
\text { buruk sapi } \\
\text { gilo }\end{array}$ & $\begin{array}{l}\text { Pemimpin yang } \\
\text { membawah } \\
\text { kehancuran bagi } \\
\text { tempat yang } \\
\text { dipimpinnya }\end{array}$ & Sindiran \\
\hline 4 & $\begin{array}{l}\text { Mancunglah } \\
\text { pipi dari } \\
\text { idung }\end{array}$ & $\begin{array}{l}\text { Orang yang rela } \\
\text { melakukan apa } \\
\text { saja agar tujuan } \\
\text { tercapai }\end{array}$ & Sindiran \\
\hline 5 & $\begin{array}{l}\text { Abu } \\
\text { segenggam } \\
\text { idak tebeli }\end{array}$ & $\begin{array}{l}\text { Orang yg dipan- } \\
\text { dang rendah } \\
\text { karena miskin }\end{array}$ & Sindiran \\
\hline 6 & $\begin{array}{l}\text { Orang makan } \\
\text { cempedak } \\
\text { awak kenai } \\
\text { getahnyo }\end{array}$ & $\begin{array}{l}\text { Orang yang } \\
\text { berbuat kita } \\
\text { yang } \\
\text { menanggung } \\
\text { akibatnya }\end{array}$ & Sindiran \\
\hline 7 & $\begin{array}{l}\text { Lunaklah gigi } \\
\text { dari pado } \\
\text { lidah }\end{array}$ & $\begin{array}{l}\text { Orang yang } \\
\text { pandai merayu } \\
\text { bila mempunyai } \\
\text { tujuan tertentu }\end{array}$ & Sindiran \\
\hline 8 & $\begin{array}{l}\text { Cupak belum } \\
\text { masak } \\
\text { ciriklah } \\
\text { betaburan }\end{array}$ & $\begin{array}{l}\text { Sesuatu belum } \\
\text { tentu kepastian- } \\
\text { nya tetapi sudah } \\
\text { diberitahukan } \\
\text { pada orang lain }\end{array}$ & Sindiran \\
\hline 9 & $\begin{array}{l}\text { Ota gedang } \\
\text { cirik kere }\end{array}$ & $\begin{array}{l}\text { Orang yang } \\
\text { perkataannya } \\
\text { selalu bohong }\end{array}$ & Sindiran \\
\hline 10 & $\begin{array}{l}\text { Angek-angek } \\
\text { cirik ayam }\end{array}$ & $\begin{array}{lr}\text { Orang } & \text { yang } \\
\text { sifatnya serba } \\
\text { tidak menentu }\end{array}$ & Sindiran \\
\hline 11 & $\begin{array}{l}\text { Lubuk kecik } \\
\text { buayo } \\
\text { banyak }\end{array}$ & $\begin{array}{l}\text { Daerahnya kecil } \\
\text { tetapi banyak } \\
\text { sekali terdapat } \\
\text { orang jahatnya }\end{array}$ & Sindiran \\
\hline
\end{tabular}

\begin{tabular}{|c|c|c|c|}
\hline No & Patos & Etos & Logos \\
\hline 12 & $\begin{array}{l}\text { Tungkek } \\
\text { bawok rebah }\end{array}$ & $\begin{array}{l}\text { Orang yang } \\
\text { menghancurkan } \\
\text { sesuatu yang } \\
\text { padahal mesti ia } \\
\text { tegakkan }\end{array}$ & Sindiran \\
\hline 13 & $\begin{array}{l}\text { Tuo anjing } \\
\text { celako kudo } \\
\text { biduk ado } \\
\text { ndak } \\
\text { berenang } \\
\end{array}$ & $\begin{array}{l}\text { Orang yang } \\
\text { perbuatannya } \\
\text { menyusahkah } \\
\text { dirinya sendiri }\end{array}$ & Sindiran \\
\hline 14 & $\begin{array}{l}\text { Gerobak idak } \\
\text { begemok }\end{array}$ & $\begin{array}{l}\text { Orang yang } \\
\text { keadaannya } \\
\text { susah dan tidak } \\
\text { mempunyai } \\
\text { masa depan } \\
\text { yang baik }\end{array}$ & Sindiran \\
\hline 15 & $\begin{array}{l}\text { Idak lapuk } \\
\text { kek ujan idak } \\
\text { lekang kek } \\
\text { pane }\end{array}$ & $\begin{array}{l}\text { Orang yang } \\
\text { merasa sok } \\
\text { hebat terhadap } \\
\text { orang lain }\end{array}$ & Sindiran \\
\hline 16 & $\begin{array}{l}\text { Ado udang di } \\
\text { balik batu }\end{array}$ & $\begin{array}{lr}\text { Orang } & \text { yang } \\
\text { menolong } & \text { jika } \\
\text { ada maunya saja }\end{array}$ & Sindiran \\
\hline 17 & $\begin{array}{l}\text { Beledang } \\
\text { makan } \\
\text { kawan }\end{array}$ & $\begin{array}{l}\text { Orang yang me- } \\
\text { nyakiti teman- } \\
\text { nya sendiri }\end{array}$ & Sindiran \\
\hline 18 & $\begin{array}{l}\text { Utang } \\
\text { tebayar } \\
\text { langsa idak }\end{array}$ & $\begin{array}{lr}\text { Orang } & \text { yang } \\
\text { pekerjaannya } \\
\text { tidak pernah } \\
\text { selesai dan } \\
\text { cendrung }\end{array}$ & Sindiran \\
\hline 19 & $\begin{array}{l}\text { Selero } \\
\text { gedang } \\
\text { tenago } \\
\text { kurang }\end{array}$ & $\begin{array}{l}\text { Orang yang } \\
\text { keinginannya } \\
\text { banyak tetapi } \\
\text { tidak bisa } \\
\text { melakukan apa- } \\
\begin{array}{l}\text { apa dalam } \\
\text { berkerja }\end{array} \\
\end{array}$ & Sindiran \\
\hline 20 & 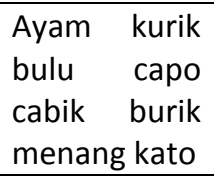 & $\begin{array}{l}\text { Orang yang tidak } \\
\text { mau kalah dalam } \\
\text { berbicara }\end{array}$ & Sindiran \\
\hline 21 & $\begin{array}{l}\text { Kudo lamo } \\
\text { lah dikan- } \\
\text { dangkan } \\
\end{array}$ & $\begin{array}{lr}\text { Pemimpin yang } \\
\text { sudah tidak } \\
\text { berkuasa lagi }\end{array}$ & Sindiran \\
\hline 22 & $\begin{array}{l}\text { Singkok daun } \\
\text { nampak } \\
\text { buah }\end{array}$ & $\begin{array}{l}\text { Orang yang } \\
\text { berbicara tanpa } \\
\text { dipikir dahulu } \\
\text { akibat dari pem- } \\
\text { bicaraannya itu }\end{array}$ & Sindiran \\
\hline
\end{tabular}


Keterangan tabel:

Patos : bentuk dari retorika kias sindir dalam bahasa Melayu Bengkulu.

Etos : makna dari retorika kias sindir dalam bahasa Melayu Bengkulu.

Logos : fungsi dari retorika kias sindir dalam bahasa Melayu Bengkulu.

\section{(b) Nasihat}

Nasihat adalah suatu ajaran atau didikan yang berasal dari seseorang (Poerwadarminta dalam Tarigan, 1993:157). Oleh karena itu, dapatlah dipahami bahwa nasihat merupakan suatu pernyataan yang digunakan untuk menyampaikan suatu maksud yang berupa ajaran atau didikan. Sedangkan rincian Temuan penelitian mengenai makna pragmatik pepatah yang berupa nasihat, dapat dilihat pada tabel berikut ini:

Tabel 2: Klasifikasi Pepatah Berdasarkan Makna Pragmatik Berupa Nasihat

\begin{tabular}{|c|c|c|c|}
\hline No & Patos & Etos & Logos \\
\hline 1 & $\begin{array}{l}\text { Jangan } \\
\text { suko } \\
\text { menjago } \\
\text { buntut } \\
\text { orang } \\
\text { buntut kito } \\
\text { sendiri } \\
\text { dicatuk } \\
\text { ayam }\end{array}$ & $\begin{array}{lr}\text { Bila } & \text { suka } \\
\text { membicarakan aib } \\
\text { seseorang maka } \\
\text { nantinya } \\
\text { sendiri juga akan } \\
\text { dibicarakan orang } \\
\text { lain }\end{array}$ & Nasihat \\
\hline 2 & $\begin{array}{l}\text { Idak ado } \\
\text { eme } \\
\text { bongkah } \\
\text { diasah }\end{array}$ & $\begin{array}{l}\text { Jika tidak memiliki } \\
\text { harta benda maka } \\
\text { haruslah berusaha } \\
\text { untuk mencarinya }\end{array}$ & Nasihat \\
\hline 3 & $\begin{array}{l}\text { Pilih-pilih } \\
\text { tebu } \\
\text { tepilih } \\
\text { tebu busuk }\end{array}$ & $\begin{array}{l}\text { Terlalu pemilih } \\
\text { dalam mencari } \\
\text { jodoh akibatnya } \\
\text { mendapatkan } \\
\text { jodoh yang tidak } \\
\text { disukai }\end{array}$ & Nasihat \\
\hline 4 & $\begin{array}{l}\text { Tepuk air } \\
\text { dalam } \\
\text { dulang } \\
\text { awak } \\
\text { tepuk } \\
\text { awak } \\
\text { basah }\end{array}$ & $\begin{array}{l}\text { Kita yang berbuat } \\
\text { kita pula yang } \\
\text { harus menanggung } \\
\text { akibatnya }\end{array}$ & Nasihat \\
\hline
\end{tabular}

\begin{tabular}{|c|c|c|c|}
\hline No & Patos & Etos & Logos \\
\hline 5 & $\begin{array}{l}\text { Baru } \\
\text { nengok } \\
\text { kilek ikan } \\
\text { tu ajo lah } \\
\text { tau lanang } \\
\text { kek } \\
\text { tinonyo }\end{array}$ & $\begin{array}{lr}\text { Sifat } & \text { seseorang } \\
\text { baik atau jahat } \\
\text { dapat } & \text { diketahui } \\
\text { dari } & \text { tingkah } \\
\text { lakunya } & \end{array}$ & Nasihat \\
\hline 6 & $\begin{array}{l}\text { Kalo idak } \\
\text { ado } \\
\text { berado } \\
\text { idak } \\
\text { tempoo } \\
\text { beSarang } \\
\text { rendah }\end{array}$ & $\begin{array}{lr}\text { Suatu persoalan } \\
\text { tidaklah mungkin } \\
\text { dapat muncul jika } \\
\text { tidak r ada } \\
\text { penyebabnya }\end{array}$ & Nasihat \\
\hline 7 & $\begin{array}{l}\text { Narik } \\
\text { rambut } \\
\text { dalam } \\
\text { tepung } \\
\text { rambut } \\
\text { idak putus } \\
\text { tepung } \\
\text { idak } \\
\text { beserak } \\
\end{array}$ & $\begin{array}{l}\text { Pemimpin haruslah } \\
\text { berlaku adil dan } \\
\text { bijaksana terhadap } \\
\text { rakyatnya }\end{array}$ & Nasihat \\
\hline 8 & $\begin{array}{l}\text { Gedang } \\
\text { besayo } \\
\text { kecik } \\
\text { beambo }\end{array}$ & $\begin{array}{l}\text { Berbicara dengan } \\
\text { seseorang haruslah } \\
\text { memperhatikan } \\
\text { usia dan statusnya }\end{array}$ & Nasihat \\
\hline 9 & $\begin{array}{l}\text { Kalo } \\
\text { belayar } \\
\text { jangan } \\
\text { lupo ingek } \\
\text { kek pulau }\end{array}$ & $\begin{array}{l}\text { Bila berpergian } \\
\text { jangan lupa } \\
\text { terhadap tujuan } \\
\text { yang dimiliki }\end{array}$ & Nasihat \\
\hline 10 & $\begin{array}{l}\text { Kalo takut } \\
\text { disembur } \\
\text { ombak } \\
\text { jangan } \\
\text { tinggal di } \\
\text { tepi laut }\end{array}$ & $\begin{array}{l}\text { Jika tidak mau } \\
\text { mendapatkan } \\
\text { suatu resiko tidak } \\
\text { usalah mendekati } \\
\text { hal yang } \\
\text { menyebabkannya }\end{array}$ & Nasihat \\
\hline 11 & $\begin{array}{l}\text { Kendak } \\
\text { balam padi } \\
\text { rebah } \\
\text { kawan } \\
\text { ngantuk } \\
\text { sorongkan } \\
\text { bantal }\end{array}$ & $\begin{array}{l}\text { Seseorang yang } \\
\text { hanya } \\
\text { mengharapkan } \\
\text { bantuan dari orang } \\
\text { lain untuk dapat } \\
\text { mewujudkan } \\
\text { keinginannya }\end{array}$ & Nasihat \\
\hline 12 & $\begin{array}{l}\text { Rezeki } \\
\text { musang } \\
\text { idakkan } \\
\text { dapek kek } \\
\text { elang }\end{array}$ & $\begin{array}{lr}\text { Tidak perlulah } \\
\text { berebut dalam } \\
\text { mencari rezeki } \\
\text { karena Tuhan telah } \\
\text { mengaturnya } \\
\text { untuk setiap orang }\end{array}$ & Nasihat \\
\hline
\end{tabular}




\begin{tabular}{|c|l|l|l|}
\hline No & \multicolumn{1}{|c|}{ Patos } & \multicolumn{1}{|c|}{ Etos } & Logos \\
\hline 13 & $\begin{array}{l}\text { Limbek } \\
\text { kecik } \\
\text { gedang } \\
\text { besungut } \\
\text { lapan }\end{array}$ & $\begin{array}{l}\text { Suatu acara baik } \\
\text { dilaksanakan } \\
\text { dengan meriah } \\
\text { ataupun hanya } \\
\text { sederhana adalah } \\
\text { tetap sama }\end{array}$ & Nasihat \\
\hline 14 & $\begin{array}{l}\text { Sekali } \\
\text { uncang } \\
\text { tebukak } \\
\text { duo tigo } \\
\text { utang } \\
\text { tebayar }\end{array}$ & $\begin{array}{l}\text { Sekali bertindak } \\
\text { sudah dapat } \\
\text { mengatasi } \\
\text { beberapa } \\
\text { persoalan }\end{array}$ & Nasihat \\
\hline 15 & $\begin{array}{l}\text { Kerbau } \\
\text { idakkan } \\
\text { mati } \\
\text { makan } \\
\text { rumput }\end{array}$ & $\begin{array}{l}\text { Tidaklah perlu } \\
\text { takut terhadap } \\
\text { suatu resiko dari } \\
\text { perbuatan yang } \\
\text { biasa kita kerjakan }\end{array}$ & Nasihat \\
\hline
\end{tabular}

\section{(2) Perumpamaan}

Perumpamaan merupakan suatu kalimat kias yang mengungkapkan kelakuan seseorang (kelompok orang) dengan cara mengambil perbandingan antara suatu kenyataan dengan keadaan lain yang terdapat di alam sekitar. Berdasarkan makna pragmatik yang terkandung di dalamnya, kias sindir yang berbentuk perumpamaan dapat dikelompokkan menjadi dua jenis yang berbeda, yaitu 1) sindiran dan 2) nasihat.

\section{(a) Sindiran}

Keraf (2000:143) berpandangan bahwa sindiran adalah suatu acuan yang ingin mengatakan sesuatu dengan makna atau maksud berlebihan dari apa yang terkandung dalam rangkaian katakatanya. Oleh karena itu, dapatlah dipahami bahwa sindiran merupakan suatu pernyataan yang digunakan untuk menyampaikan suatu maksud yang berupa ejekan.Adapun rincian Temuan penelitian mengenai makna pragmatik perumpamaan yang berupa sindiran, dapat dilihat pada tabel berikut ini:
Tabel 3: Klasifikasi Perumpamaan Berdasarkan Makna Pragmatik Berupa Sindiran

\begin{tabular}{|c|c|c|c|}
\hline No & Patos & Etos & Logos \\
\hline 1 & $\begin{array}{l}\text { Macam } \\
\text { idung } \\
\text { pelepa } \\
\text { kelapo }\end{array}$ & $\begin{array}{lr}\text { Orang } & \text { yang } \\
\text { memiliki } & \text { wajah } \\
\text { yang jelek } & \end{array}$ & Sindiran \\
\hline 2 & $\begin{array}{l}\text { Cak } \\
\text { nurunkan } \\
\text { anak ayam }\end{array}$ & $\begin{array}{l}\text { Orang yang } \\
\text { melibatkan } \\
\text { keluarganya jika } \\
\text { sedang berselisih } \\
\text { dengan orang lain }\end{array}$ & Sindiran \\
\hline 3 & $\begin{array}{l}\text { Macam } \\
\text { tukak kek } \\
\text { kain buruk }\end{array}$ & $\begin{array}{l}\text { Sepasang kekasih } \\
\text { yang } \\
\text { hubungannya } \\
\text { tidak dapat } \\
\text { dipisahkan }\end{array}$ & Sindiran \\
\hline 4 & $\begin{array}{l}\text { Macam } \\
\text { negak } \\
\text { benang } \\
\text { basah } \\
\end{array}$ & $\begin{array}{l}\text { Masalah yang } \\
\text { sangat sulit untuk } \\
\text { diselesaikan }\end{array}$ & Sindiran \\
\hline 5 & $\begin{array}{l}\text { Cak pipit } \\
\text { ngulam } \\
\text { jagung }\end{array}$ & $\begin{array}{l}\text { Kemampuan kecil } \\
\text { tetapi keinginan } \\
\text { terlalu besar }\end{array}$ & Sindiran \\
\hline
\end{tabular}

(3) Nasihat

Poerwadarminta (dalam Tarigan, 1993:157) menyatakan nasihat adalah suatu ajaran atau didikan yang berasal dari seseorang. Oleh karena itu, dapatlah dipahami bahwa nasihat merupakan suatu pernyataan yang digunakan untuk menyampaikan suatu maksud yang berupa ajaran atau didikan. Sedangkan rincian Temuan penelitian mengenai makna pragmatik perumpamaan yang berupa nasihat, dapat dilihat pada tabel berikut ini:

Tabel 4: Klasifikasi Perumpamaan Berdasarkan Makna Pragmatik Berupa Nasihat

\begin{tabular}{|l|l|l|l|}
\hline No & \multicolumn{1}{|c|}{ Patos } & \multicolumn{1}{|c|}{ Etos } & Logos \\
\hline 1 & $\begin{array}{l}\text { Macam } \\
\text { kucing } \\
\text { beranak }\end{array}$ & $\begin{array}{l}\text { Orang yang suka } \\
\text { sekali berpindah- } \\
\text { pindah tempat } \\
\text { atau rumah }\end{array}$ & Nasihat \\
\hline 2 & $\begin{array}{l}\text { Macam } \\
\text { timun } \\
\text { bengkok } \\
\text { karung }\end{array}$ & $\begin{array}{l}\text { Orang yang } \\
\text { berkerja tetapi } \\
\text { tidak dihargai dan } \\
\text { diberi upah }\end{array}$ & Nasihat \\
\hline
\end{tabular}




\begin{tabular}{|l|l|l|l|}
\hline No & \multicolumn{1}{|c|}{ Patos } & \multicolumn{1}{|c|}{ Etos } & Logos \\
\hline & $\begin{array}{l}\text { masuk } \\
\text { direken } \\
\text { idak }\end{array}$ & & \\
\hline 3 & $\begin{array}{l}\text { Cak kucing } \\
\text { kenai lidi }\end{array}$ & $\begin{array}{l}\text { Orang yang } \\
\text { sangat takut } \\
\text { terhadap sesuatu }\end{array}$ & Nasihat \\
\hline
\end{tabular}

\section{Pembahasan}

Berdasarkan kajian terhadap retorika kias sindir dalam bahasa Melayu Bengkulu, maka ditemukanlah bahwa bentuk retorika kias sindir dalam bahasa Melayu Bengkulu yang sering digunakan oleh masyarakat suku Melayu Bengkulu di kehidupan sehari-harinya adalah terbagi atas dua jenis yang berbeda, yaitu 1) pepatah dan 2) perumpamaan.

Penggolongan suatu retorika kias sindir ke dalam jenis pepatah ataupun perumpamaan, didasarkan terhadap ada atau tidaknya kata-kata pembanding (laksana, sebagai, seperti, bak; ibarat, bagai, bagaikan, seumpama, macam, umpama, dan kata sejenisnya) yang melekat di dalam kias sindir tersebut (Tarigan, 1993:160). Di mana ciri dari suatu pepatah dapat diketahui dari tidak adanya kata-kata pembanding dalam pengungkapannya (Keraf, 1994:248). Sedangkan ciri dari suatu perumpamaan dapat dikenali dari selalu digunakanya kata-kata pembanding dalam pengungkapannya (Akhadiah dkk., 1993:59). Adapun penjelasan yang lebih rinci dapat dilihat berikut ini:

\section{1) Pepatah}

Pepatah merupakan peribahasa yang mengandung nasihat atau ajaran dari orang-orang tua, yang juga dapat dipahami sebagai ungkapan untuk mematahkan perkataan orang. Di mana kiasan dalam pepatah tidak dinyatakan dengan kata-kata pembanding, karena yang dikiaskan dalam pepatah adalah suatu keadaan atau kelakuan seseorang (Keraf, 1994:248).

Penggolongan suatu retorika kias sindir ke dalam jenis pepatah, didasarkan terhadap tidak adanya kata-kata pembanding (laksana, sebagai, seperti, bak; ibarat, bagai, bagaikan, seumpama, macam, umpama, dan kata sejenisnya) yang melekat di dalam kias sindir tersebut (Tarigan, 1993:160). Di mana ciri khusus dari suatu pepatah dapat diketahui dari tidak terdapatnya katakata pembanding dalam pengungkapannya (Keraf, 1994:248).

Oleh karena itu, dapatlah dipahami bahwa pepatah sebenarnya merupakan suatu kalimat kias yang berisi nasihat atau ajaran yang berasal dari orang-orang yang memiliki pengetahuan mendalam tentang kehidupan. Melalui penelitian yang penulis lakukan, ditemukanlah bahwa bentuk retorika kias sindir dalam bahasa Melayu Bengkulu yang berupa pepatah, ternyata memiliki kesamaan dengan bentukbentuk pepatah, yang bukan saja terdapat dalam rumpun bahasa Melayu secara umum, tetapi juga terdapat pada semua golongan bahasa suku bangsa yang ada di Indonesia (Pamuntjak dalam Tarigan, 1993:156).

Berdasarkan makna pragmatik yang terkandung di dalam kias sindir yang berbentuk pepatah, maka secara rinci dapat dikelompokkanlah pepatah ke dalam dua jenis yang berbeda, yaitu 1) sindiran dan 2) nasihat. Adapun penjelasan yang lebih rinci dapat dilihat berikut ini:

\section{(a) Sindiran}

Menurut Keraf (2000:143) sindiran adalah suatu acuan yang ingin mengatakan sesuatu dengan makna atau 
maksud berlebihan dari apa yang terkandung dalam rangkaian katakatanya. Oleh karena itu, dapatlah dipahami bahwa sindiran ialah suatu pernyataan yang digunakan untuk menyampaikan suatu maksud yang berupa ejekan.

Dengan kata lain, sindiran merupakan kata atau kelompok kata yang ditujukan untuk mengolok-olok seseorang sehingga mengalami ketersinggungan atau dapat dipahami sebagai suatu bahasa yang menyatakan hal bertentangan dengan tujuan untuk mengolok-olok (Poerwadarminta dalam Tarigan, 1985:92).

Berdasarkan Temuan penelitian penulis, ditemukanlah bahwa makna pragmatik berupa sindiran yang terkandung di dalam retorika kias sindir yang berbentuk pepatah, ternyata memiliki fungsi sebagai: 1) sindiran terhadap tingkah laku dari seseorang, dan 2) sindiran terhadap tingkah laku dari sekelompok orang.

\section{(b) Nasihat}

Nasihat merupakan suatu ajaran atau didikan yang berasal dari seseorang (Poerwadarminta dalam Tarigan, 1993:157). Oleh karena itu, dapatlah dipahami bahwa nasihat adalah suatu pernyataan yang digunakan untuk menyampaikan suatu maksud yang berupa ajaran atau didikan. Berdasarkan Temuan penelitian penulis, ditemukanlah bahwa makna pragmatik berupa nasihat yang terkandung di dalam retorika kias sindir yang berbentuk pepatah, ternyata memiliki fungsi sebagai: 1) nasihat atau pedoman pengajaran kepada seseorang dan 2) nasihat atau pedoman pengajaran kepada sekelompok orang.

\section{2) Perumpamaan}

Perumpamaan

merupakan

kalimat untuk mengungkapkan sesuatu, membandingkan suatu kenyataan dengan keadaan lain yang terdapat dalam alam semesta ini (Surana, 2004:7).

Penggolongan suatu retorika kias sindir ke dalam jenis perumpamaan, didasarkan terhadap adanya kata-kata pembanding (laksana, sebagai, seperti, bak; ibarat, bagai, bagaikan, seumpama, macam, umpama, dan kata sejenisnya) yang melekat di dalam kias sindir tersebut (Tarigan, 1993:160). Di mana ciri khusus dari suatu perumpamaan dapat dikenali dari selalu digunakanya kata-kata pembanding dalam pengungkapannya (Akhadiah dkk., 1993:59).

Melalui penelitian yang penulis lakukan, ditemukanlah bahwa bentuk retorika kias sindir dalam bahasa Melayu Bengkulu yang berupa perumpamaan, ternyata memiliki kata-kata pembanding, yaitu berupa kata 'macam' (seperti) dan kata 'cak' (seperti). Hal ini tentu saja memiliki kesamaan dengan bentukbentuk perumpamaan, yang terdapat pada semua bahasa suku bangsa yang ada di Indonesia (Tarigan, 1993:160).

Oleh karena itu, dapatlah
dipahami bahwa perumpamaan
merupakan suatu kalimat kias yang mengungkapkan kelakuan seseorang (kelompok orang) dengan cara mengambil perbandingan antara suatu kenyataan dengan keadaan lain yang terdapat di alam sekitar. Berdasarkan makna pragmatik yang terkandung di dalam kias sindir yang berbentuk perumpamaan, maka secara rinci dapat dikelompokkanlah perumpamaan ke dalam dua jenis yang berbeda, yaitu 1) sindiran dan 2) nasihat. 


\section{(a) Sindiran}

Poerwadarminta (dalam Tarigan, 1985:92) menyatakan bahwa sindiran merupakan kata atau kelompok kata yang ditujukan untuk mengolok-olok seseorang sehingga mengalami ketersinggungan atau dengan kata lain sindiran dapat dipahami sebagai suatu bahasa yang menyatakan hal bertentangan dengan tujuan untuk mengolok-olok.

Berdasarkan Temuan penelitian penulis, ditemukanlah bahwa makna pragmatik berupa sindiran yang terkandung di dalam retorika kias sindir yang berbentuk perumpamaan, ternyata memiliki fungsi sebagai: 1) sindiran terhadap tingkah laku dari seseorang, dan 2) sindiran terhadap tingkah laku dari sekelompok orang.

\section{(b) Nasihat}

Nasihat merupakan ajaran yang diberikan dari orang-orang tua (Keraf 1994:248). Berdasarkan Temuan penelitian penulis, ditemukanlah bahwa makna pragmatik berupa nasihat yang terkandung di dalam retorika kias sindir yang berbentuk perumpamaan, ternyata memiliki fungsi sebagai: 1) nasihat atau pedoman pengajaran kepada seseorang dan 2) nasihat atau pedoman pengajaran kepada sekelompok orang.

\section{Simpulan}

Berdasarkan pembahasan mengenai kajian retorika kias sindir dalam bahasa Melayu Bengkulu, maka dapat diperoleh suatu pemahaman bahwa jenis dari retorika kias sindir dalam bahasa Melayu Bengkulu dapat dikelompokkan menjadi pepatah dan perumpamaan. Sedangkan makna pragmatik dari retorika kias sindir dalam bahasa Melayu Bengkulu, berdasarkan fungsi sosial kegunaannya dapat digolongkan menjadi sindiran terhadap tingkah laku dari seseorang atau sekelompok orang dan nasihat atau pedoman pengajaran kepada seseorang atau sekelompok orang.

\section{Implikasi}

Temuan penelitian mengenai kajian retorika kias sindir dalam bahasa Melayu Bengkulu ini, dapat diimplementasikan ke dalam mata pelajaran bahasa, sastra Indonesia dan daerah, khususnya bagi Sekolah Menengah Pertama (SMP) dan Sekolah Menengah Atas (SMA) yang terdapat di Provinsi Bengkulu. Temuan penelitian ini sangat tepat jika diadopsikan ke dalam materi pembelajaran mengenai peribahasa, sehingga nantinya dapat memperkaya pemahaman siswa mengenai berbagai jenis dan makna pragmatik dari retorika kias sindir yang terdapat dalam bahasa Melayu Bengkulu. Sedangkan pada tingkat Perguruan Tinggi (PT), terutama pada Program Studi Pendidikan Bahasa, Sastra Indonesia dan Daerah, Temuan penelitian ini tentu saja sangat bermanfaat dalam memperkaya materi pembelajaran pada mata kuliah retorika.

\section{Saran}

Pada saat sekarang ini tidak semua orang dapat memahami maksud dari retorika kias sindir dalam bahasa Melayu Bengkulu. Hal itu dikarenakan retorika kias sindir dalam bahasa Melayu Bengkulu sudah sangat jarang digunakan di dalam masyarakat Melayu Bengkulu. Untuk itulah, diperlukan suatu usaha bersama dalam menjaga dan melestarikan kias sindir tersebut agar nantinya kias sindir yang terdapat dalam 
bahasa Melayu Bengkulu itu dapat diwariskan kepada generasi yang akan datang.

Melihat pentingnya keberadaan retorika kias sindir dalam bahasa Melayu Bengkulu bagi kehidupan masyarakat suku Melayu Bengkulu, maka untuk itu diperlukan suatu usaha yang konkrit dalam rangka untuk mempertahankannya. Salah satu cara yang dianggap baik dan dapat dengan segera dilaksanakan adalah dengan mengumpulkan sebanyak mungkin kias sindir yang masih hidup di dalam masyarakat suku Melayu Bengkulu, guna nantinya agar dapat disusun menjadi kamus kias sindir.

\section{Daftar Pustaka}

Akhadiah, Sabarti dkk. 1993. Bahasa Indonesia. Jakarta: Departemen Pendidikan dan Kebudayaan.

Keraf, Gorys. 1994. Terampil Berbahasa Indonesia 2. Jakarta: Departemen Pendidikan dan Kebudayaan.

Keraf, Gorys. 1996. Linguistik Bandingan Historis. Jakarta: Gramedia Pustaka Utama.

Keraf, Gorys. 2000. Diksi dan Gaya Bahasa. Jakarta: Gramedia Pustaka Utama.

Margono, S. 2005. Metodologi Penelitian Pendidikan. Jakarta: Rineka Cipta.

Narbuko, Cholid dan Achmadi, H. Abu. 2005. Metodologi Penelitian. Jakarta: Bumi Aksara.

Sudaryanto. 1982. Metode Linguistik: Kedudukannya, Aneka Jenisnya, dan Faktor Penentu Wujudnya. Yogyakarta: Universitas Gadja Mada.
Sudaryanto. 1988a. Metode Linguistik: Bagian Pertama ke Arah Memahami Metode Linguistik. Yogyakarta: Gadja Mada University Press.

Sudaryanto. 1988b. Metode Linguistik: Bagian Kedua Metode dan Aneka Teknik Pengumpulan Data. Yogyakarta: Gadja Mada University Press.

Sudaryanto. 1990. Aneka Konsep Kedataan Lingual dalam Linguistik. Yogyakarta: Duta Wacana University Press.

Suryabrata, Sumadi. 2000. Metodologi Penelitian. Jakarta: Raja Grafindo Persada.

Safnil. 2003. Pengantar Analisis Retorika Teks. Bengkulu: Perpustakaan Unib Press.

Surana. 2004. Pengantar Sastra Indonesia. Jakarta: Tiga Serangkai.

Sugiyono. 2005. Memahami Penelitian Kualitatif. Bandung: Alfabeta.

Sugiyono. 2008. Metode Penelitian Pendidikan: Pendekatan Kuantitatif, Kualitatif, dan $R \& D$. Bandung: Alfabeta.

Tarigan, Henry Guntur. 1985. Pengajaran Gaya Bahasa. Bandung: Angkasa.

Tarigan, Henry Guntur. 1993. Pengajaran Semantik. Bandung: Angkasa.

Trianto, Agus. 2000. Analisis Retorika Humor Mahasiswa. Laporan Penelitian tidak diterbitkan. Bengkulu: Lembaga Penelitian Universitas Bengkulu.

Yule, George. 2006. Pragmatik. Yogyakarta: Pustaka Pelajar. 